\title{
Developing Metacognitive Model On In-Service Teacher's Academic Writing Through Virtual Flipped Classroom
}

\author{
Enny Dwi Lestariningsih ${ }^{1}$, Testiana Deni Wijayatiningsih ${ }^{2 *}$ \\ Pendidikan Bahasa dan Sastra Indonesia, Universitas Terbuka, Indonesia ${ }^{1}$ \\ Pendidikan Bahasa Inggris, Universitas Muhammadiyah Semarang, Indonesia ${ }^{2 *}$ \\ ennyd1@ecampus.ut.ac.id, *testiana@unimus.ac.id
}

DOI: 10.20884/1.jli.2021.12.1.2828

\begin{abstract}
Article History:
First Received:

ABSTRACT

$26 / 06 / 2020$

The current study has two objectives. The first is to describe the process of

Final Revision: developing a metacognitive model on in-service teachers' academic writing

$01 / 03 / 2021$

Available online: through virtual flipped classrooms and then secondly, to investigate the teachers' research writing interests using a metacognitive model on in-service teachers' academic writing through virtual flipped classrooms. This research

$30 / 06 / 2021$ was conducted in the Demak regency. The researchers also used the Research and Development method. Validation results exemplify that the application of a metacognitive model to academic writing in the in-service teachers through virtual flipped classroom specifically used appropriate teaching materials to be used in classroom teaching, the attention is given to the outcomes of the validation, such as; the concept of conformance indicators, material performance indicators, demonstration indicators, and capability indicators. This proves that the metacognitive model on in-service teachers' academic writing through virtual flipped classroom applications runs smoothly and according to what is expected. In addition, it has positive interests from the teachers which could give good impact in their writing research article.
\end{abstract}

Keywords: metacognitive model; flipped classroom; academic writing

\section{INTRODUCTION}

In-service teachers are required to carry out their responsibilities in writing academic articles according to their competence and complete further professional competence. They are also required to create a Classroom Action Research writing as a means of developing their research that is adapted to their real learning process in their respective classes. In addition to teaching and giving knowledge to their students, they also have to carry out research and complete the administration of learning in the classroom. In this case, they are required to behave professionally without disturbing one of their respective duties and responsibilities. To anticipate their duties and responsibilities, research opportunities can be done in classroom teaching. So that research that 
supports their profession, particularly in classroom learning, studies on classroom action, since the core of the study is designed to represent and enhance the condition and features in the classroom interactions.

Because of the above problems, the in-services teachers only did research based on the grade of their students and they did not use some guidelines to do Classroom Action Research. In this case, the researchers also note and reflect on the various disadvantages and advantages of the application of the metacognitive model on in-service teachers' academic writing through the virtual flipped classroom in the Classroom Action Research (CAR) course. The implementation of the tutorial is believed strongly to stimulate students to be able to congregate proposals and Classroom Action Research (CAR) reports with a metacognitive model on in-service teachers' academic writing through the virtual flipped classroom. Based on pre-observation, in-service teachers have the roles and obligations of teaching, investigating, and assessing learning outcomes. Furthermore, the low motivation of in-service teachers to write proposals and CAR academic writing made them lack research articles knowledge and mechanism.

In addition, the tutorial is taught using traditional models and there has been no challenging progress in line with technological advances that can encourage CAR academic writing on the sidelines of students acting like a school teacher. Interested models, teaching strategies that are appropriate for the classroom environment, application media, metacognitive model, and virtual flipped classroom are considered to help the development of written works in the context of CAR academic literature. It is here that teaching designs and teaching materials are needed that are interesting and support the design of their respective studies without decreasing the time they instruct and administer by way of metacognitive model and virtual flipped classroom. As stated by Gredler (2011), metacognitive demands learners to think actively and creatively. Metacognitive accentuates the understanding of one's thought process. Meanwhile, Hackers, Keener, and Kircher (2009), writing may be performed inside a metacognitive system consisting of the level of the object and the metalevel. The regulation and supervising strategies are at the level of the item. The strategy shall be defined as a plan or method for achieving the objectives and in terms of writing, and the objective of controlling the strategy shall be considered. Based on pre observations, researchers can conclude the obstacles faced in the process of designing CAR academic writing, especially t often have difficulty in determining the title of the academic writing and the in-serviceteacher cannot complete the CAR academic writing on time. Other observations were also found in the tutorials given them were still confusing because only giving the module without writing workshop, collaborating with interesting learning models, and motivating them to write. In line 
with these complex issues, there is a need for reflection and development on interesting writing models that make the implementation of tutorials more effective. Change and reflection are done through the application of the metacognitive model and virtual flipped classroom in Classroom Action Research workshops as a stimulus so that in-service teachers are more active and creative in preparing CAR academic writing. The use of virtual flipped classrooms had different from Basal's s study (2015) which discussed that Flipped classrooms benefited from four types based on the subject matter review of the feedback: one-to-one instruction, advanced student training, managing time limitations in the classroom, and classroom participation. Besides, a technique that can be applied to teachers and lecturers in ways that simplify the amount of direct guidance in their teaching activities and at the same time increasing the knowledge of each other is called flipped classrooms. This approach incorporates technology that administers new resources for learners with learning materials that can be used and viewed online. (Brent, 2013). Besides, according to Bergmann and Sams (2012) is the environment that's usually nailed to the classroom is now done at home, and what's conventionally done as homework is now settled at home. Whereas this research applied virtual flipped classroom that is synchronous learning virtual face to face using Microsoft team and the online or asynchronous using what app group is flexible to apply in global COVID 19 epidemic. This is in line with the previous research from Vliet, E. A. V., Winnips, J.C., and Brouwer, N. (2015) that suggests that periodic use of flipped classes in the curriculum to conduct metacognition and immersive learning approaches workable. This is the gap that the virtual flipped classroom is different from the flipped classroom. The virtual flipped classroom based on the metacognitive model is used to overcome the global COVID 19 epidemic in Indonesia and all over the world.

Based on the summary of the barriers faced above, the researchers can draw up the problem as follows:

a. How is the development of the metacognitive model and virtual flipped classroom in the Classroom Action Research workshops for in-service teachers?

b. Do the implementation of the metacognitive model and virtual flipped classroom in the Classroom Action Research workshops for in-service teachers improve their interest in writing research?

\section{MATERIALS AND METHOD}

The research and development method is an analysis technique whose primary objective is to create an accurate device and test the efficacy of the implementation of the device. According 
to Sugiyono (2010), R\&D (Research and Development) is to manufacture products and assess the efficacy of these products. Requirements for the manufacture of certain products and the assessment of product efficacy. One research and development model is a revised model of the development of the instructional system for Thiagarajan, Semmel, and Semmel (4-D models). Identifying (design), creating (design), generating (producing), spreading (spreading) consists of this development model. Broadly speaking, the stages of developing teaching materials in this study used a 4-D model which was modified into three stages, namely define, design, and develop.

This current study altered the 4-D model which is simplified into three stages from four stages because of the real condition in the research site. The three stages were definition, designing, developing, which were implemented in this study. Dissemination (spread) is not applied because of the duration of research, the implementation considerations, and the fact which a good device (valid) has been developed at the stage of production (development). The participants were 20 inservice teachers from Demak Regency.

The stages of research and development of the 4-D model Sugiyono (2010) are explained as follows: (1) The define phase aims to define and define learning conditions beginning with an analysis of the objectives of the boundaries of the material developed by the device, where the activities carried out are define / define and limit what is the scope of the development of metacognitive model and virtual flipped classroom in Classroom Action Research (CAR) workshops; (2) The design phase aims to prepare a prototype of the CAR academic writing design and the design of CAR teaching materials where the initial activities make the initial design of the teaching device components and teaching materials; (3) The develop phase aims to produce teaching devices and teaching materials based on metacognitive model and virtual flipped classroom in the CAR workshops that have been revised based on input from experts, where the activities carried out are develop teaching devices and teaching materials that have been designed by making improvements based on input from experts to achieve the modified teaching device along with optimal teaching materials; (4) In addition to evaluating the efficacy of the use of devices in teaching and learning practices, the phase of dissemination is the phase of the use of devices that have been developed on a broader scale, for instance in other classes, disseminate stages are not conducted due to research time constraints and consideration at development (development) has produced a good device (valid) and accompanied by teaching materials. 


\section{Research Procedure}

The procedure for developing this model is described as follows:

a. Define phase (defining)

By analyzing the objectives and boundaries of the content, this designating phase proposes to identify and exemplify the learning needs. Activities in this definition include the study of the CAR workshops' tutorial syllabus and tutorial plan through tutorial discussions with observers, indicator analysis, idea analysis, task analysis, student analysis, examination of applicable research to resolve current issues, and literature reviews on supporting theories.

b. Design phase

The goal of this stage is to design teaching devices in such a way that the form of a metacognitive model and virtual flipped classroom-based teaching materials and academic writing are created. The results of the design process called draft 1.

c. Develop phase (development)

The goal of this stage is to create a proposal for a good teaching instrument. Activities at this stage involved the validation of small-scale experiments and field trials. The reason for this stage is as follows.

1) Expert validation is carried out to receive feedback for development as well as expert assessments (validators) on the nature of metacognitive models and virtual flipped classroom teaching tools and collaborative writing (draft 1). The validation of metacognitive models and virtual flipped classroom learning resources and teaching materials based on teaching materials is carried out by experts in their fields. Based on the findings of the expert validation, revisions to the equipment and instruments were carried out to create a draft 2 that was appropriate for use.

2) Test the questionnaire sheet and the observation sheet to be used at the field trial stage. Tests of questionnaire sheets and observation sheets have been sent to 20 in-service teachers who have taken the Classroom Action Testing Course. A small test is performed to reflect the approved learning device (draft 2). The simulation findings in the small trial class were analyzed and updated to acquire a metacognitive model and virtual flipped classroom resources to be used for field testing (draft 3).

3) Field trials

Testing of revised learning devices (draft 3) was performed in the Classroom Action Study (CAR) tutorial class. At the end of the meeting, the students also received a questionnaire to find out the students' reaction to the use of metacognitive models and virtual flipped 
classroom teaching materials that had been created. Observers who track student behaviors accompany researchers during teaching and learning. After studying, researchers and analysts focus on the practices that have been conducted. The results of the reflection shall be used to base the revision.

\section{Method of Collecting Data}

The data gathered by applied the following methods.

a. Questionnaire

The researchers used the questionnaire to collect information on the validator response after the CAR workshops checked the learning materials, syllabus, and tutorial schedule.

b. Observation

Observations were created and gathered to acquire some information on CAR learning outcomes in field trials using the learning tools created. In addition, the observation approach was often used to assess the validity of learning devices using a checklist procedure.

c. Test

The test used in the application in a small class gave other results to support the data collection.

\section{Data and Data Retrieval Techniques}

Data are facts or parts of facts that contain meaning associated with reality. The data used in this current research consist of qualitative and quantitative data. Qualitative data are the validity of learning devices, student responses, and the level of knowledge of students before and after the study. Quantitative data is the validity data of the device.

Determination of Research Success

This research is aimed to have been fruitful if:

a. The learning devices shall be deemed legitimate when the validators give the score in the good or very good category.

b. The action research writing performance acheives $70 \%$,

c. the learners have a positive interest more than $70 \%$ in joining the class

\section{RESULTS \& DISCUSSION}

\section{Results}

The procedure for developing this metacognitive model and virtual flipped classroom is described as follows; 
a. Define Stage (Defining)

At this defining point, researchers have established and defined learning needs by evaluating the goals and boundaries of the material. The activities to be described include a CAR tutorial plan and syllabus analysis through tutor discussions with observers, indicator analysis, concept analysis, task analysis, student analysis, reviewing relevant research to answer existing problems, and literature studies on theories supporters. The results obtained can be described as follows;

Analysis of Action Research tutorial plans and syllabus

In this part of the analysis, the researchers discussed with the tutors and observers about CAR tutorial plans and syllabus workshops.

b. Stage Design

The goal of this stage is to construct teaching devices in such a way that the form of a metacognitive model and virtual flipped classroom teaching materials is created. The results of the design process are hereinafter referred to as Draft 1.

c. Stage Develop (Development)

The goal of this stage is to create a plan for a good teaching instrument. Activities at this level require the validation of small-scale experiments and field trials. The reason for this stage is as follows.

1) Expert validation is performed to receive feedback for change as well as expert reviews (validators) on the nature of metacognitive models and virtual flipped classroom resources (draft 1). The validation of metacognitive models and virtual flipped classroom tools and teaching materials based on teaching materials is carried out by experts in their fields. Based on the findings of the expert validation, revisions to the equipment and instruments were carried out to create a draft 2 that was appropriate for use.

2) Test the questionnaire sheet and the observation sheet to be applied at the field trial stage. Tests of questionnaires and observation sheets were sent to 20 in-service teachers who had taken part in the Classroom Action Testing workshops. A small study is administered to represent a validated learning device (draft 2). The simulation findings in the small trial class were analyzed and updated to acquire a metacognitive model and virtual flipped classroom resources to be used for field testing (draft 3 ). 
The researchers applied the validity and reliability study of student motivation sheets to the implementation of the metacognitive model and the simulated flipped classroom. In addition, the researcher discusses the findings of the study outlined in the exposure below.

1) Results of the Validity of Student Activeness Questionnaires

The results of this validation analysis shall be determined based on the Arikunto (2009) validation formula as follows;

$$
r_{x y}=\frac{N \Sigma X Y-(\Sigma X)(\Sigma Y)}{\sqrt{\left\{N \Sigma X^{2}-(\Sigma X)^{2} \int\left(N \Sigma Y^{2}-(\Sigma Y)^{2}\right\}\right.}}
$$

From the results of the calculations using the above formula, the results of the question are true in the encouragement of the students to ask as many as 15 questions as they are valid and there are 10 questions in question number $1,3,7,8,9,10,11,13,14$ and 15 . It can be inferred from these findings that only 10 questions will be included in this study since only 10 are valid.

2) The findings of the reliability review suggest that the questions in the questionnaire were entered in the accurate group. This is shown by the estimation of reliability using the following formula;

$$
\mathbf{r}_{11}=\left(\frac{\mathrm{k}}{\mathrm{k}-1}\right)\left(1-\frac{\sum \sigma_{i}^{2}}{\sigma_{t}^{2}}\right)
$$

(Arikunto,2009)

The reliability of the questionnaire data results is at 0.74 , which means that the question can be used for testing purposes.

3) Ground trials

In the Classroom Action Study (CAR) tutorial workshops, trials of revised learning devices (draft 3 ) were performed. At the end of the workshop, the students also received a questionnaire to find out the students' reaction to the use of metacognitive models and virtual flipped classroom materials that had been created. Observers who track student behaviors accompany researchers during teaching and learning. After studying, researchers and analysts focus on the practices that have been conducted. Reflecting findings had an objective to revise the learning tools which can be displayed in Figure 2. 


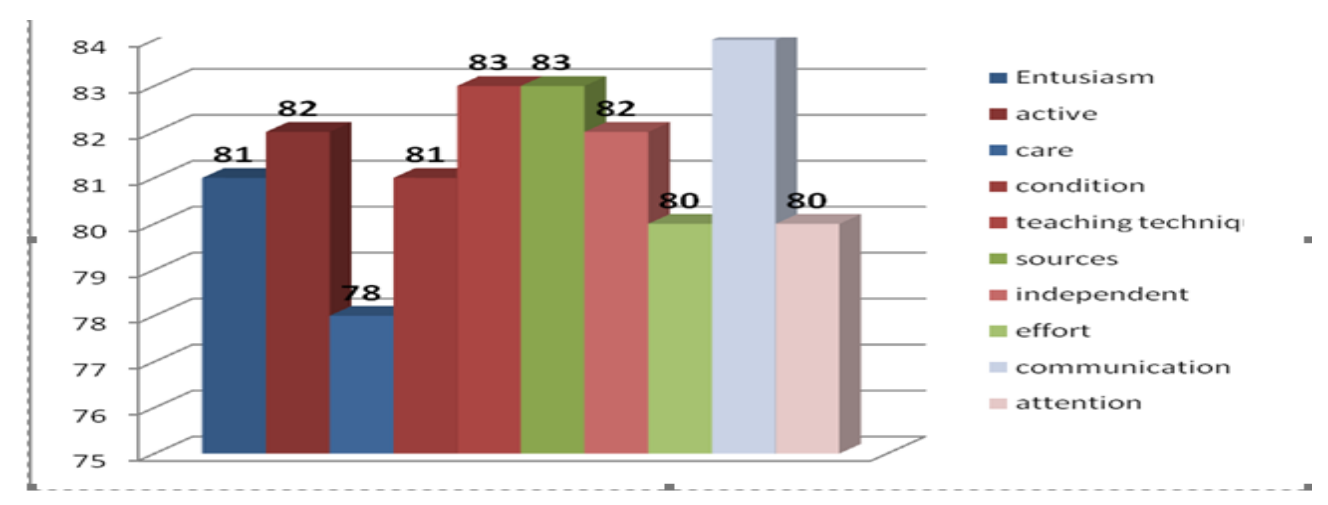

Figure 2. The Result of Observation before Implementation Related to Students' Interest

The result of observations before applying the metacognitive model and virtual flipped classroom application was still low standard. In this case, it needed an improvement to be a success in writing action research.

In addition, the result of validation from the experts came to the valid category because it got an average score of more than 4. It means that all the criteria of validation namely syllabus, tutorial plans, Materials, the individual quiz had a good category. The findings can be depicted in the table below.

Table 1. Validation Results

\begin{tabular}{llllll}
\hline No & Validator & \multicolumn{4}{c}{ Validation Results } \\
\cline { 3 - 6 } & & RAT & SAT & Materials & Quiz \\
\hline 1 & 1 & 4,03 & $\mathbf{4 , 0 2}$ & $\mathbf{4 , 8}$ & $\mathbf{4 , 9}$ \\
2 & $\mathbf{2}$ & $\mathbf{4 , 2 5}$ & $\mathbf{4 , 1 0}$ & $\mathbf{4 , 9}$ & $\mathbf{4 , 2 0}$ \\
\hline & Criteria & Valid & Valid & Valid & Valid \\
\hline
\end{tabular}

Moreover, the result of observation in applying the metacognitive model and virtual flipped classroom can be explicated below.

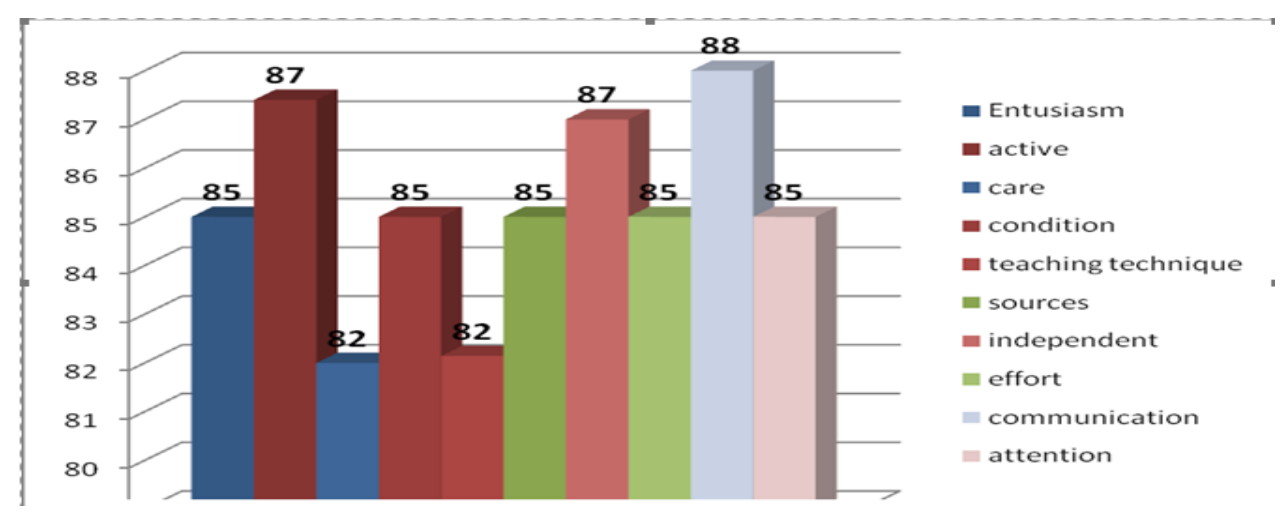

Figure 3. The Results of Observation 
From these results, it can be inferred that the student's interest increases with the application of a metacognitive model and a virtual flipped classroom to teaching materials and learning devices in the tutorial class. This is known from the findings of the student's observation of interest. The students were enthusiastic about academic writing because they are encouraged to learn to write collaboratively and concentrate on metacognitive models, so that they are increasingly involved in generating weighty ideas, particularly in class action research. This means that CAR (Class Action Research) tutorial workshops can be used to apply a metacognitive model and a virtual flipped classroom to learning and teaching materials.

The findings of the independent quiz evaluation have improved the effectiveness of answering questions and assessing the problems posed by metacognitive model-based tutors, with an average pre-test score of 65 percent increasing to 80 percent. This means that students have an improved capacity to grasp and apply a metacognitive paradigm and a virtual flipped classroom.

\section{Findings}

From the analysis of the above research, the findings can be gathered that the implementation of the metacognitive model and virtual flipped classroom is appropriate to be used in 1 Classroom Action Research tutorial workshops for in-service teachers. The findings of the study indicate that the expert's validation explicitly applying teaching materials are suitable for implementing in classroom teaching tutorials, the concept of conformance indicators, material performance indicators, demonstration indicators, and capability indicators, and the tutorial module is designed using CAR. Besides, the implementation of a metacognitive model and a virtual flipped classroom is compatible with the in-service cognitive style of teachers so they can build their information and writing processes that can discuss their research subject in a virtual flipped classroom. So, they can research this pandemic situation by virtual flipped classrooms. This result cognates with Veenman, et. al. (2006) that discussed metacognition as a person's knowledge of the way and the process of thinking or its own. Furthermore, CAR academic writing produced by in-service teachers is also following the stages in the metacognitive model from Hacker, Keener, dan Kircher (2009) research which argued that writing may be systematized in a metacognitive structure consisting of the level of the object and the metalevel. The regulation and supervising technique is including in the metacognitive structure. The strategy is defined as a plan or method for achieving objectives and in terms of writing, and the objective of controlling the strategy is considered. The monitoring technique aims to observe the development of thinking concepts. This process helps develop the ability of students to put their ideas into writing. Control strategies 
applied to generate ideas, selecting ideas, setting goals, plan, translating, drafting, revising and editing. In each control strategy, they can engage well through virtual flipped classrooms which enable them to meet virtually through the Microsoft team's application and what app group application. While the monitoring strategies have four steps, reading, re-reading, reviewing, and reflecting. This is where the role of the teacher plays to provide basic rules in the revision process, for example by determining what should be commented on or revised.

In addition, the findings of learners' self-perception achieved strong community while joining CAR academic writing at the tutorial workshop. In addition, the learners' self-perception experiences achieved positive development in metacognitive models and virtual flipped classroom applications, especially through the use of teaching materials. This shows that the metacognitive model and virtual flipped classroom applications run smoothly and as planned. Besides, the interest of students to follow the tutorial of the workshop after being submitted has a positive interest in learning tutorials and getting excited in joining the classroom activities. In this discussion, the engagement of the learners in the identification of research problems, the determination of the theoretical basis, and the determination of the research methodology according to the path chosen have progressed well and are now at an active stage and can think critically when formulating a new approach.

\section{CONCLUSION}

Based on the findings of the current study, the researchers can deduce the concluding summary as follows.

1) The findings of the validation state that the use of a metacognitive model and flipped classroom, in particular the use of teaching materials, is suitable to implement in the classroom teaching tutorials, got reliable validation results which viewed from the concept of conformance indicators, material performance indicators, demonstration indicators and capability indicators with the tutorials and syllabus.

2) Student interests that are strong at interpreting the content and engaging in action studying in the classroom. Moreover, the learner's interest increased well above the $70 \%$ performance indicator in the metacognitive model and flipped classroom applications, particularly using developmental materials. This shows that the metacognitive model and flipped classroom applications run smoothly and as planned.

3) The learner's test value increases from $65 \%$ for the pre-test to $80 \%$ in the post-test. These findings revealed that the implementation of a metacognitive model and flipped classroom 
enhances the reasoning skills and comprehension of Classroom Action Study (CAR) academic writing.

To sum up, this current research proves that the metacognitive strategy in writing the academic article by integrating with the flipped classroom achieves positive responses and develops the students' writing academic performances.

\section{REFERENCES}

Arikunto, S. (2009). Prosedur Penelitian: Suatu Pendekatan Praktek (5th ed). Jakarta: Rineka Cipta.

Basal, Ahmet. (2015). The implementation of a flipped classroom in foreign language teaching. Turkish Online Journal of Distance EducationTOJDE October ISSN 1302- 6488 Volume: 16 Number: 4 Article 3.

Bergmann, J., \& Sams, A. (2012). Flip your classroom: Reach every student in every class every day. Eugene, OR: ISTE.

Brent. J, Graham. (2013). Student perceptions of the flipped classroom. Columbia: The University of British Columbia.

Collado-Valero, J., Rodríguez-Infante, G., Romero-González, M., Gamboa-Ternero, S., NavarroSoria, I., \& Lavigne-Cerván, R. (2021). Flipped Classroom: Active Methodology for Sustainable Learning in Higher Education during Social Distancing Due to COVID-19. Sustainability, 13(10), 5336. MDPI AG. Retrieved from http://dx.doi.org/10.3390/su13105336.

Gredler, M. E. (2011). Learning and instruction: Teori dan aplikasi (edisi keenam). Jakarta: Kencana Prenada Media Group.

Hacker, D. J., Keener, M. C., \& Kircher J. C. (2009). Writing is applied metacognition. In D. J. Hacker, J. Dunlosky, A. C. Graesser (Eds.), Handbook of metacognition in education (pp. 154172). New York, NY: Routledge. doi:10.4324/9780203876428.ch9.

Ismail, S. S.; Abdulla, S. A. Virtual flipped classroom: New teaching model to grant the learners knowledge and motivation. "JOTSE: Journal of Technology and Science Education", Març 2019, vol. 9, núm. 2, p. 168-183. DOI: 10.3926/jotse.478.

Istianingrum, A., \& Karnawati, R. (2020). Efektivitas Virtual Classroom dan Flip the Teacher dalam Flipped Classroom pada Chuukyuu Bunpou. Journal of Japanese Language Education and Linguistics, 4(2), 115-131. doi:https://doi.org/10.18196/jjlel.4238.

Mariyana, R. (2020). Pengembangan Desain Model Pembelajaran Virtual Flipped Classroom. Jurnal Pembelajaran Inovatif, 3(2), 150 - 156. https://doi.org/10.21009/JPI.032.10.

Rachmat, M., Muliastuti, L., \& Emzir, E. (2020). The Implementation of Flipped Classroom Learning Model in Teaching Paragraph Writing. Loquen: English Studies Journal, 13(2), 103-115. doi:10.32678/loquen.v13i2.3573s.

Sugiyono. (2010). Metode penelitian pendidikan pendekatan kuantitatif, kualitatif, dan $R \& D$. Bandung : Alfabeta. 
Veenman, Marcel V. J., Van Hout-Wolters, Bernadette H. A. M. dan Afflerbach, Peter. (2006). Metacognition and Learning: Conceptual and Methodological Considerations. Metacognition Learning, 1: 3-14. DOI 10.1007/s11409-006-6893-0.

Vliet, E. A. V., Winnips, J.C. and Brouwer, N. (2015). Flipped-class pedagogy enhances student metacognition and collaborative-learning strategies in higher education but the effect does not persist. CBE Life Sciences Education, 4(3): ar26. DOI: 10.1187/cbe.14-09-0141. 